\title{
Does the Occupational Activity Level Affect the Quality of Life of Patients Treated with Epidural Steroid Injections for Lumbar Disc Herniations?
}

\author{
Vikram Arun Mhaskar, Sudhir Pai \\ Department of Orthopaedics, St. Johns Medical College Hospital, Bangalore, India
}

Study Design: Prospective cohort study.

Purpose: To determine whether there was any change in the quality of life of patients in sedentary/non sedentary occupations treated with epidural steroid injection for lumbar disc herniations using the 8 components of the SF 36 questionnaire.

Overview of Literature: No previously done similar study published.

Methods: Ninety patients comprising sedentary and non sedentary occupations with lumbar disc herniations on magnetic resonance imaging who were treated with epidural steroid injection at St. Johns Hospital Bangalore who met the Spinal Outcomes Research Trial eligibility criteria from April 2009 to May 2010.

Results: Of the 90 patients evaluated 44 were of Sedentary and 46 were of non sedentary activity levels, At 6 months primary outcomes physical functioning $(p=0.573$, in difference between sedentary and non sedentary, improvement $p=0.001)$ energy/fatigue (difference between the two $p=0.917$, improvement $p=0.001$ ), emotional well being (difference $p=0.912$, improvement, $p=0.001$ ), social functioning (difference $p=0.523$, improvement $p=0.232$ ), pain (difference $p=0.535$, improvement $p=0.001$ ), general health (difference $p=0.738$, improvement $p<0.001$ ).

Conclusions: There was a statistically significant improvement in patients of both the sedentary and non sedentary groups $p<0.001$ in all components of the SF36 in both sedentary and non sedentary patients except social functioning where the improvement was not statistically significant, and there was no significant difference between non sedentary and sedentary populations over time.

Key Words: Occupational activity level, Quality of life, Epidural steroids, Lumbar disc herniation, SF 36

\section{Introduction}

Back pain is now an international health issue of major significance. About $80 \%$ suffer from this at some time in their life, ranked as the most frequent cause of limitation of activity in people younger than 45 years by the National centre For Health Statistics [1]. Disc prolapse accounts for $5 \%$ of lower back disorders and is one of the most common causes for surgery [2]. Several epidemiological studies show a relationship between lumbar disc diseases and physical workplace factors such as lifting or carrying of loads, forward bending, and whole body vibrations [3]. Treatment for lumbar disc herniation can be conservative or surgical and which one is effective is always controversial. Epidural steroid injection is a very popular and low risk alternative to surgical intervention in lumbar disc herniation. It enjoys reasonable success rates for alleviation of radicular symptoms from lumbar herniated discs.

The development of lumbar disc herniation has been linked positively with occupational levels of activity in various previously done studies [2].

Received Jun 1, 2011; Revised Jun 22, 2011; Accepted Jul 25, 2011

Corresponding author: Vikram Arun Mhaskar, MBBS

Department of Orthopaedics, St. Johns Medical College Hospital,

Sarjapur Road, Bangalore 560034, India

Tel: +918025530494, Fax: +918041508685, E-mail: mhaskar2001@yahoo.com

Copyright (C) 2012 by Korean Society of Spine Surgery

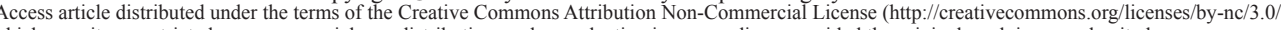
which permits unrestricted non-commercial use, distribution, and reproduction in any medium, provided the original work is properly cited. Asian Spine Journal • pISSN 1976-1902 eISSN 1976-7846 


\section{Definition of sedentary occupations}

The ability to perform the full range of sedentary work requires the ability to lift no more than 10 pounds at a time and occasionally to lift or carry articles like docket files, ledgers, and small tools. Although a sedentary job is defined as one that involves sitting, a certain amount of walking and standing is often necessary in carrying out job duties. Jobs are sedentary if walking and standing are required occasionally and other sedentary criteria are met. "Occasionally" means occurring from very little up to one- third of the time, and would generally total no more than about 2 hours of an 8-hour workday. Sitting would generally total about 6 hours of an 8-hour workday. Unskilled sedentary work also involves other activities, classified as "non-exertional," such as capacities for seeing, manipulation, and understanding, remembering, and carrying out simple instructions [4].

\section{Definition of non sedentary occupations}

These include occupations that have greater levels of activity than that mentioned above. The effectiveness of epidural steroid injection in treating patients with lumbar disc herniation employed in various different occupations with varied physical activity levels has not been completely studied. This study is basically a prospective cohort study that intends to answer the following question.

Does a positive dose-response relationship exist between occupational lumbar activity levels and the affectivity of epidural steroid injection in patients with lumbar disc herniation on magnetic resonance imaging (MRI) who met the Spinal Outcomes Research Trial [5] eligibility criteria?

\section{Materials and Methods}

In as well as out-patients with evidence of lumbar disc herniation on MRI, low back ache, with or without radiculopathy for at least 6 weeks were evaluated. A total of 90 patients in the age group 20 to 65 years were evaluated from April 2009 -May 2010 at St. Johns Medical College Hospital Bangalore. These patients were administered the SF 36 questionnaire just before the epidural steroid was given, 2 weeks after, then 1 month and 6 months after treatment to assess the changes in quality of life which were an indirect indicator of the affectivity of the treatment.

The patient was allowed to resume full activity levels after 2 days of rest.
The exclusion criteria in selecting the patients were: 1) Back pain for less than 6 weeks, those without evidence of lumbar disc herniation on MRI; 2) Those who are asymptomatic with or without evidence of lumbar disc herniation on MRI imaging; 3) Osseous cause for lumbar canal stenosis on MRI imaging; 4) Signs of lumbar disc degeneration without lumbar disc herniation; 5) Cauda equina syndrome.

The patients were divided into sedentary as well as non sedentary occupations. The sedentary occupations included housewives with servants and software professionals without much physical activities. In the non sedentary group we included farmers (manual labourers) and traffic policemen. There were 44 members in the sedentary group and 46 members in the non sedentary group.

All patients had either double level bulges or single level protrusions. Forty patients had double level bulges and 50 patients had single level protrusions. A written informed consent was taken from all the patients and no interventions were done.

\section{Epidural steroid injection dosage and procedure}

The patient is positioned in the left lateral position/sitting in the epidural steroid injection room. The level of the disc is pre determined by MRI. The drugs to be injected are kept ready. The mixture used contains $40 \mathrm{mg}$ Triamcinolone acetate which corresponds to approximately $4 \mathrm{ml}$, mixed with $4 \mathrm{ml}$ of $0.5 \%$ sensorcaine and $12 \mathrm{ml}$ of normal saline to make a $20 \mathrm{ml}$ mixture. This mixture is then injected in the epidural space one level higher to the level of greatest disc herniation causing compression.

An IV canula should be placed in situ for at least 4 hours to be able to tackle any hypotension that ensues. The mixture is then injected into the epidural space.

\section{Results}

Of the 90 patients evaluated 44 were of Sedentary and 46 were of non sedentary activity levels, at 2 weeks, 1 month and 6 months primary outcomes of physical functioning, social functioning, general health, emotional, visual analogue scale, energy and pain (Table 1) were evaluated and same outcomes for single level protrusions (50 patients) and double level bulges ( 40 patients) were measured (Table 2). 
Table 1. Bulge versus protrusion

\begin{tabular}{|c|c|c|c|}
\hline & Bulge & Protrusion & $p$-value \\
\hline \multicolumn{4}{|c|}{ Visual analogue scale } \\
\hline Baseline & $63.8 \pm 25.1$ & $72.3 \pm 15.1$ & \\
\hline Follow-up 1 & $48.2 \pm 18.9$ & $48.0 \pm 16.8$ & \\
\hline Follow-up 2 & $34.2 \pm 23.5$ & $44.0 \pm 25.4$ & $<0.001$ \\
\hline Follow-up 3 & $27.6 \pm 32.6$ & $37.7 \pm 35.9$ & 0.573 \\
\hline \multicolumn{4}{|c|}{ Physical functioning } \\
\hline Baseline & $39.8 \pm 23.6$ & $41.3 \pm 24.0$ & \\
\hline Follow-up 1 & $58.6 \pm 21.4$ & $55.3 \pm 26.0$ & \\
\hline Follow-up 2 & $73.0 \pm 19.9$ & $60.7 \pm 26.2$ & $<0.001$ \\
\hline Follow-up 3 & $78.8 \pm 21.9$ & $65.0 \pm 29.5$ & 0.07 \\
\hline \multicolumn{4}{|l|}{ Energy } \\
\hline Baseline & $44.7 \pm 12.8$ & $42.0 \pm 21.0$ & \\
\hline Follow-up 1 & $52.8 \pm 14.4$ & $47.0 \pm 11.5$ & \\
\hline Follow-up 2 & $61.2 \pm 13.1$ & $51.7 \pm 17.9$ & $<0.001$ \\
\hline Follow-up 3 & $63.6 \pm 19.0$ & $55.3 \pm 19.9$ & 0.587 \\
\hline \multicolumn{4}{|l|}{ Emotional } \\
\hline Baseline & $58.2 \pm 16.6$ & $58.9 \pm 19.2$ & \\
\hline Follow-up 1 & $68.4 \pm 15.4$ & $64.5 \pm 16.3$ & \\
\hline Follow-up 2 & $74.0 \pm 12.5$ & $67.1 \pm 15.3$ & $<0.001$ \\
\hline Follow-up 3 & $72.3 \pm 18.3$ & $73.0 \pm 17.8$ & 0.24 \\
\hline \multicolumn{4}{|c|}{ Social functioning } \\
\hline Baseline & $75.5 \pm 30.9$ & $87.5 \pm 23.1$ & \\
\hline Follow-up 1 & $85.0 \pm 21.0$ & $84.2 \pm 24.8$ & \\
\hline Follow-up 2 & $85.6 \pm 20.8$ & $86.7 \pm 20.3$ & 0.489 \\
\hline Follow-up 3 & $85.6 \pm 24.1$ & $86.7 \pm 21.9$ & 0.229 \\
\hline \multicolumn{4}{|l|}{ Pain } \\
\hline Baseline & $37.4 \pm 17.8$ & $35.5 \pm 17.1$ & \\
\hline Follow-up 1 & $49.8 \pm 13.3$ & $48.2 \pm 17.3$ & \\
\hline Follow-up 2 & $62.5 \pm 15.6$ & $50.8 \pm 13.6$ & $<0.001$ \\
\hline Follow-up 3 & $69.5 \pm 23.8$ & $61.8 \pm 25.3$ & 0.34 \\
\hline \multicolumn{4}{|l|}{ General health } \\
\hline Baseline & $58.0 \pm 23.5$ & $50.0 \pm 21.8$ & \\
\hline Follow-up 1 & $68.0 \pm 17.9$ & $58.7 \pm 21.8$ & \\
\hline Follow-up 2 & $70.6 \pm 18.7$ & $60.7 \pm 19.7$ & $<0.001$ \\
\hline Follow-up 3 & $70.3 \pm 19.5$ & $62.7 \pm 19.4$ & 0.962 \\
\hline
\end{tabular}

\section{Discussion}

There was a significant improvement in almost all parameters of the SF 36 scale in both sets of population before and after treatment. However, there was no statistically signifi- cant difference in levels of improvement in both groups.

There is statistically significant improvement in quality of life of patients who had two level bulges and one level protrusion but the difference between the two groups was not statistically significant. 
Table 2. Sedentary versus non sedentary

\begin{tabular}{|c|c|c|c|}
\hline & Bulge & Protrusion & $p$-value \\
\hline \multicolumn{4}{|c|}{ Physical functioning } \\
\hline Baseline & $39.8 \pm 23.6$ & $41.3 \pm 24.0$ & \\
\hline Follow-up 1 & $58.6 \pm 21.4$ & $55.3 \pm 26.0$ & \\
\hline Follow-up 2 & $73.0 \pm 19.9$ & $60.7 \pm 26.2$ & $<0.001$ \\
\hline Follow-up 3 & $78.8 \pm 21.9$ & $65.0 \pm 29.5$ & 0.07 \\
\hline \multicolumn{4}{|l|}{ Energy } \\
\hline Baseline & $40.3 \pm 16.4$ & $47.2 \pm 15.5$ & \\
\hline Follow-up 1 & $46.8 \pm 13.0$ & $54.5 \pm 13.3$ & $<0.001$ \\
\hline Follow-up 2 & $54.3 \pm 17.9$ & $61.1 \pm 12.3$ & 0.917 \\
\hline Follow-up 3 & $55.5 \pm 19.8$ & $65.5 \pm 18.4$ & \\
\hline \multicolumn{4}{|l|}{ Emotional } \\
\hline Baseline & $54.3 \pm 20.5$ & $62.6 \pm 12.8$ & \\
\hline Follow-up 1 & $62.3 \pm 18.4$ & $71.6 \pm 10.9$ & $<0.001$ \\
\hline Follow-up 2 & $67.5 \pm 15.9$ & $75.3 \pm 10.4$ & 0.912 \\
\hline Follow-up 3 & $67.2 \pm 18.6$ & $77.9 \pm 15.8$ & \\
\hline \multicolumn{4}{|c|}{ Social functioning } \\
\hline Baseline & $83.1 \pm 26.4$ & $76.9 \pm 30.9$ & \\
\hline Follow-up 1 & $83.8 \pm 22.9$ & $85.6 \pm 21.9$ & \\
\hline Follow-up 2 & $85.0 \pm 21.7$ & $87.0 \pm 19.5$ & 0.232 \\
\hline Follow-up 3 & $85.0 \pm 22.8$ & $87.0 \pm 23.8$ & 0.523 \\
\hline \multicolumn{4}{|l|}{ Pain } \\
\hline Baseline & $30.8 \pm 15.9$ & $42.6 \pm 17.1$ & \\
\hline Follow-up 1 & $45.1 \pm 16.8$ & $53.3 \pm 11.4$ & $<0.001$ \\
\hline Follow-up 2 & $56.4 \pm 18.9$ & $59.9 \pm 12.1$ & 0.535 \\
\hline Follow-up 3 & $63.5 \pm 25.9$ & $69.8 \pm 22.9$ & \\
\hline \multicolumn{4}{|l|}{ General health } \\
\hline Baseline & $49.0 \pm 25.4$ & $61.0 \pm 18.9$ & \multirow{4}{*}{$\begin{array}{r}<0.001 \\
0.738\end{array}$} \\
\hline Follow-up 1 & $60.8 \pm 20.5$ & $68.3 \pm 18.5$ & \\
\hline Follow-up 2 & $62.3 \pm 19.9$ & $71.5 \pm 18.2$ & \\
\hline Follow-up 3 & $63.9 \pm 17.9$ & $71.0 \pm 21.0$ & \\
\hline \multicolumn{4}{|c|}{ Visual analogue scale } \\
\hline Baseline & $71.5 \pm 23.3$ & $62.5 \pm 20.3$ & \multirow{4}{*}{$\begin{array}{r}<0.001 \\
0.738\end{array}$} \\
\hline Follow-up 1 & $52.5 \pm 17.8$ & $43.8 \pm 17.5$ & \\
\hline Follow-up 2 & $43.0 \pm 26.4$ & $32.8 \pm 21.6$ & \\
\hline Follow-up 3 & $39.8 \pm 36.9$ & $23.0 \pm 28.8$ & \\
\hline
\end{tabular}

In the Indian community especially the manual labour class and the police traffic constables, the physical fitness levels are of utmost importance in their functioning. The economic burden on the manual labour class of society is also considerable as they are many times the sole bread winners of their family and live a hand to mouth existence. They are mainly contract labourers paid on a daily wage basis. Thus they need to get back to work as fast as possible. The economic burden on the traffic constable class was also considerable, and pressure to return to work is also high. 
This study with its categorization is meaningful to the readers from the medical point of view as it explores the effective utilization of epidural steroid injection to treat lumbar disc herniation and which type of population fulfilling the inclusion exclusion criteria would benefit maximum from it. In a developing country like India where there are great disparities in wealth among populations and a rising number of software professionals with relatively sedentary lifestyles this study helps to find out whether epidural steroid benefits the tough manual labourers/working class or the patients with desk jobs? If we come to a conclusion it makes ground for a further study to explore its cost effectiveness vis a vis discectomy in these two populations.

On administering the SF 36 questionnaire which has its own fallacies mainly being due to its subjectivity, how much of the improvement of quality of life was psychological and how much was an actual improvement is questionable in this study.

The age of the patients could be a confounding factor. In a previously done study comparing work related lumbar radiculopathy versus non work related lumbar radiculopathy, there was a significantly greater improvement symptomatically in non work related patients [6].

In a previously done study comparing epidural steroid versus discectomy for lumbar disc herniation they found that epidural steroid injection was not as effective as discectomy with regard to reducing symptoms and disability associated with a large herniation of the lumbar disc. However, epidural steroid injection did have a role: it was found to be effective for up to three years by nearly one-half of the patients who had not had improvement with six or more weeks of noninvasive care.

Our results were good in both groups as possibly due to effective patient selection, appropriate indications for epidural steroid injection with appropriate inclusion/exclusion criteria and by the fact that the follow-up period was short term (6 months).

There are no other studies that have been done in the past that are similar to this study.

\section{Conclusions}

Epidural steroid was effective in improving quality of life in both sedentary and non sedentary patients over a 6 month period but the difference between the two groups was not statistically significant.

\section{Acknowledgements}

I would like to thank my statistician Mrs Sumitra for her unrelenting help in this study and my wife Dr. Parul and parents Dr. Arun and Dr. Rita Mhaskar for their support. I would also like to sincerely thank my father in law Dr J Maheshwari for being my inspiration to be an orthopaedic surgeon.

\section{REFERENCES}

1. Deyo RA. Conservative therapy for low back pain. Distinguishing useful from useless therapy. JAMA 1983;250:1057-62.

2. Carlsson AM. Assessment of chronic pain. I. Aspects of the reliability and validity of the visual analogue scale. Pain 1983;16:87-101.

3. Seidler A, Bergmann A, Jäger M, et al. Cumulative occupational lumbar load and lumbar disc disease--results of a German multi-center case-control study (EPILIFT). BMC Musculoskelet Disord 2009;10:48.

4. The Official Website of the U.S. Social Security Administration. SSR 96-9p: policy interpretation ruling [internet]. [cited 2012 Apr 16]. Availavle from: http:// www.ssa.gov/OP_Home/rulings/di/01/SSR96-09di-01.html.

5. Buttermann GR. Treatment of lumbar disc herniation: epidural steroid injection compared with discectomy. A prospective, randomized study. J Bone Joint Surg Am 2004;86:670-9.

6. Warfield CA, Crews DA. Work status and response to epidural steroid injection. J Occup Med 1987;29:315-6. 